\title{
A roadmap for the $E U$ White Paper goal on urban transport
}

\author{
H. Gudmundsson ${ }^{1}$, J. Schippl ${ }^{2}$, M. D. Leiren ${ }^{4}$, C. H. Sørensen ${ }^{1}$, \\ R. Brand ${ }^{5}, \mathrm{~K}$. Anderton ${ }^{3} \&$ M. Reichenbach ${ }^{2}$ \\ ${ }^{1}$ Department of Transport, Technical University of Denmark, Denmark \\ ${ }^{2}$ ITAS, Karlsruhe Institute of Technology, Germany \\ ${ }^{3}$ University of Oxford, UK \\ ${ }^{4}$ Transport Economics Institute, Norway \\ ${ }^{5}$ Rupprecht Consult, Germany
}

\begin{abstract}
In its 2011 Transport Policy White Paper, the European Commission introduced ten targets to be met in order to reach a more competitive and resource efficient transport system. The following dual goal focused on urban transport and commuting: "To halve the use of 'conventionally-fuelled' cars in urban transport by 2030 ; and to phase them out by 2050 ; and to achieve "essentially $\mathrm{CO}_{2}$-free city logistics in major urban centres by 2030." The question driving the research behind this paper is how to realise this dual urban transport goal for 2030, taking into consideration existing trends, available policy options, the diverse interests of stakeholders involved in urban mobility in Europe. The paper draws on data gathered in the EU FP7 TRANSFORuM project, including workshop dialogues with stakeholders representing different interests in and perspectives on urban transport and mobility. The main result is a roadmap that proposes a broad strategy to answer the question "Who has to do what, by when" to achieve the urban transport goal. The roadmap includes detailed proposals for action and milestones at different levels of decision making. This paper will describe the process of consultations and the outcomes of the roadmap process and will also discuss the perspectives for implementation.

Keywords: Urban Transport Policy, White Paper, roadmap, European Union.
\end{abstract}




\section{Introduction}

Cities are arenas for innovation, economic growth, and quality of life. According to estimates by the European Commission urban areas generate $85 \%$ of the GDP in the European Union. The urban share of the population in Europe projected to rise from $73 \%$ in 2014 to over $80 \%$ in 2050 [1]. Cities are however also major consumers of energy and polluters of the atmosphere; it has previously been calculated that urban transport accounts for around $70 \%$ of pollutants and $40 \%$ of greenhouse gas emissions from European road transport [2]. Transport in urban areas is therefore important, not only for the citizens and businesses located in the cities themselves, but also for the vitality of the European Union and as a whole. While there have been several European policy initiatives targeting urban transport, it was not until the 2011 Transport Policy White Paper that an attempt was made to set clear goals for clean urban transport at the European level [3], namely:

- "To halve the use of conventionally-fuelled cars in urban transport by 2030; and to phase them out by 2050;" and

- "To achieve essentially $\mathrm{CO}_{2}$-free city logistics in major urban centres by 2030."

The While Paper was titled as a "Roadmap to a Single European Transport Area - towards a competitive and resource efficient transport system". However, the document did in fact not develop a roadmap or strategy for how to fulfil the specified goals and targets. This was instead included as a task in the Seventh Framework Programme for Research and Technological Development of the EU. The 12-partner consortium "TRANSFORuM" was formed to respond to this call and was successful in its application. The project was initiated on February $1^{\text {st }}$ 2013, and the consortium worked closely with stakeholders over two years to create roadmaps, recommendations, and a strategic outlook for a range of goals in different areas of in the White Paper. In this paper we focus on the work to craft the roadmap for the White Paper goal for urban transport (goal 1) [4].

In section 2 we describe the methodology and processes applied in developing the roadmap. In section 3 we present the key elements and messages of the resulting roadmap, highlighted as conditions, trends, building blocks, and barriers. Section 4 presents the key messages and proposed actions of the roadmap. Finally section 5 will conclude and discuss some perspective and possible next steps.

\section{Methodology}

In order to create a strong basis for developing the roadmap the project wanted to establish a sound factual basis drawing from state-of-the-art literature, and to solicit viewpoints and ideas from a broad and robust range of urban transport stakeholders. A concept of 'fictive pathways' towards the goal was also applied. 


\subsection{Literature review}

The literature review summarized knowledge in the following three areas:

- Overview of the main policies, funding mechanisms, actors and trends in the area or urban transport an mobility in Europe

- Challenges and barriers to the implementation of White Paper goals, including factors such as limited experience with alternative transport solutions, and goal conflicts in local transport planning

- Selection and analysis of international case studies, including examples to demonstrate if transformations are in fact possible

The analysis in each area considered theoretical contributions (e.g. concepts of 'implementation barriers', and 'good practice'), as well as empirical evidence available (for example on funding mechanisms, and case studies, related to sustainable urban transport in Europe). Special attention was given to accumulate results from already existing European research projects and platforms. The key findings were captured in report deliverables but more importantly also in summary documents and slide presentations for the stakeholder workshops.

\subsection{Stakeholder dialogues}

Stakeholder consultations and dialogues were the main mechanisms engaged to collect and consolidate insights from a wide range of interests. An underlying assumption was that a legitimate roadmap could not be purely scientifically driven, nor emerge from a linear top-down process. It must be based on a shared understanding of a variety of stakeholders' interests and perspectives, and to elicit coordinated ideas for action. The consultation process was therefore designed to facilitate a joint consideration of key observations as well as the collective emergence of synergetic ideas.

First of all it was necessary to provide for a rich and balanced representation of all types of stakeholders, while taking into account the limited scope and resources of the project. Building from the existing networks of project partners supplemented with extensive research and outreach TRANSFORuM developed a database covering 1,000 individuals representing nearly as many organisations, fields of expertise and interest. The selection of a limited number of stakeholders to engage in the urban transport dialogue process was based on criteria defined in TRANSFORuM's methodology for shaping the TRANSFORuM Network. To further ensure the complete transparency of this process lists of attendees of the events are available on the project website.

The participants invited to urban transport workshops covered representatives of city and regional administrations; producers and developers of vehicles and energy technologies; transport operators and mobility service providers; businesses and experts involved in freight and urban logistic services, representatives of citizen organisations, think tanks and other NGOs; and members of national and European programmes and platforms supporting clean urban mobility. It was also important to ensure a good balance between different 
regions in Europe, between the two genders, and between established as well as emerging players in the urban transport field.

The Urban Thame held four two-day workshops in Gdansk, Poland (June 2013), Oslo, Norway (October 2013), Vienna, Austria (January 2014) and Copenhagen, Denmark (2014). At these events invited stakeholders discussed conditions and opportunities for delivering the Urban Transport goal, and, later in the process, draft versions of the roadmap.

In addition to the workshops, we conducted seven personal interviews with seven stakeholders, who represented interests less well covered in the workshops, including car sharing organisations, and logistic providers. The TRANSFORuM partners also joined several events where different constellations of stakeholders offered their perspectives on key aspects of clean and efficient urban transport. The concluding input was collected at the TRANSFORuM conference on December 8, 2014, where a panel of stakeholders gave their positive - and critical - remarks to prepare the finally condensed version of the roadmap.

\section{3 'Fictive pathways'}

One of the tools that was used to successfully support the dialogue process was the concept of 'fictive pathways'. The fictive pathways represent scenarios of three different imagined, but presumably not unrealistic cities in Europe. Each is set in a different context in terms of space, traditions and economy, and explores its own unique trajectory towards fulfilling the White Paper goal of halving conventional vehicle use, and provide $\mathrm{CO}_{2}$-free logistics.

The fictive cities were first outlined in broad terms by the TRANSFORuM consortium, and then developed in more detail by different teams of stakeholders, in terms of what could be available policy options and strategies in each context. Finally the consortium refined each case into a unique 'example pathways' towards the EU urban transport goal, complete with governance frameworks, policy measures and milestone targets. This approach was particularly helpful to uncover the wide diversity of conditions and opportunities among European cites, but also to illustrate the mutual dependencies among factors like socio-economic conditions, technical opportunities, and cultural preferences. The examples can be seen in the final roadmap.

\section{Conditions and building blocks}

This section describes key results of the first phase of the process, aiming to establish a shared knowledge platform for developing the roadmap. To support the process towards answering the question 'of who is to do what, by when' it was decided to address the starting conditions for a goal oriented urban transport strategy, already existing drivers and trends, the available strategic options for change, and the likely barriers for employing the most effective means. 


\subsection{Conditions}

\subsubsection{Stakeholders}

Urban passenger and freight transport are driven, influenced and balanced by a wide range of interacting factors and trends, within geography, economy, technology, culture, society and politics [5]. Some, like dieselisation of the vehicle fleet, are macro scale trends affecting all urban areas to some degree; others are specific to the national context, like privatisation of urban bus services in the UK, while others again are somewhat unique for each city, such as canals in Venice, or near-zero emission electricity in Oslo. 'Urban transport stakeholders' therefore encompass a wide span of actors at several different levels, across public, private and civil sector. Lacking co-operation or coordination among stakeholders within generally fragmented governance systems [6] is likely to pose severe challenges for the effective implementation of policies to reach towards a uniform transport goal across Europe.

\subsubsection{Trends}

Most scenario studies predict that transport demand will further increase in the future [7]. Some forecasts, however, project a general stabilization and possible decline in urban transport demand in Europe over the coming decades [8]. However, due to strong variation in local circumstances neither growth, nor decline will necessarily apply in the same way to all cities in the north, south, east and west of Europe.

Trends expected to be important for the future of urban transport include ones such as urbanisation, urban sprawl, ageing of the population, lifestyle changes among young generations, energy price development, technologic innovations, and the proliferation of e-commerce. The direction of change with regard to the impact of such trends on urban mobility patterns are however not always clear. For example, young persons in some urban areas today tend to travel less by private car than the same age group did a decade earlier [9]. Meanwhile, owning a car remains a status symbol in many countries and the younger generation may still wish to get one when needs and opportunities converge.

Another trend is a shift in vehicle and fuel technologies. New types such as hybrids, electric, natural gas and ethanol-fuelled vehicles are emerging, although at present they only have a few percent of the new vehicle market. It is impossible to predict which one of these, or any other alternatives, will be future 'winners' and 'losers'. Nationally specific, often temporary governmental support program are strongly influencing the trends today, more than market pull. Different trends will also interact in context dependent ways, such as when fuel prices influence the vehicle and housing markets, and subsequently life style choices $[10,11]$. In short, clear, uniform trends for urban transport in Europe were not identified.

\subsection{Strategic building blocks}

Literature review and stakeholder consultations jointly confirmed that there are multiple possible set of actions and measures that could contribute to reach the 
urban transport goal. Taking into account that the goal speaks of vehicle use and logistics (rather than simply vehicles numbers and fleets), it was decided in TRANSFORuM to consider the following three strategic areas:

- Technological substitution of conventionally-fuelled passenger cars;

- Reduced use of private passenger cars and enhancement of alternatives;

- Increased use of low carbon city logistics technologies and practices.

Within and across these strategic areas, changes in supply and demand would need to supplement and reinforce each other, in order to transform the production and consumption of urban mobility. Generic types of change were defined as 'strategic building blocks', as for example alternatively fuelled vehicles, shared use of cars, and freight consolidation (Figure 1).

The differentiation between passenger and goods strategies is relevant because of the different character of the transport functions and services, the different types of vehicles, and the different stakeholders involved. The differentiation between technology substitution and activity change is relevant because of the different types of policy measures and scales of intervention required to influence them. While all of the building blocks will need to be activated to reach the European urban transport goal, individual cities and Member States will clearly request and apply different combinations of measures.

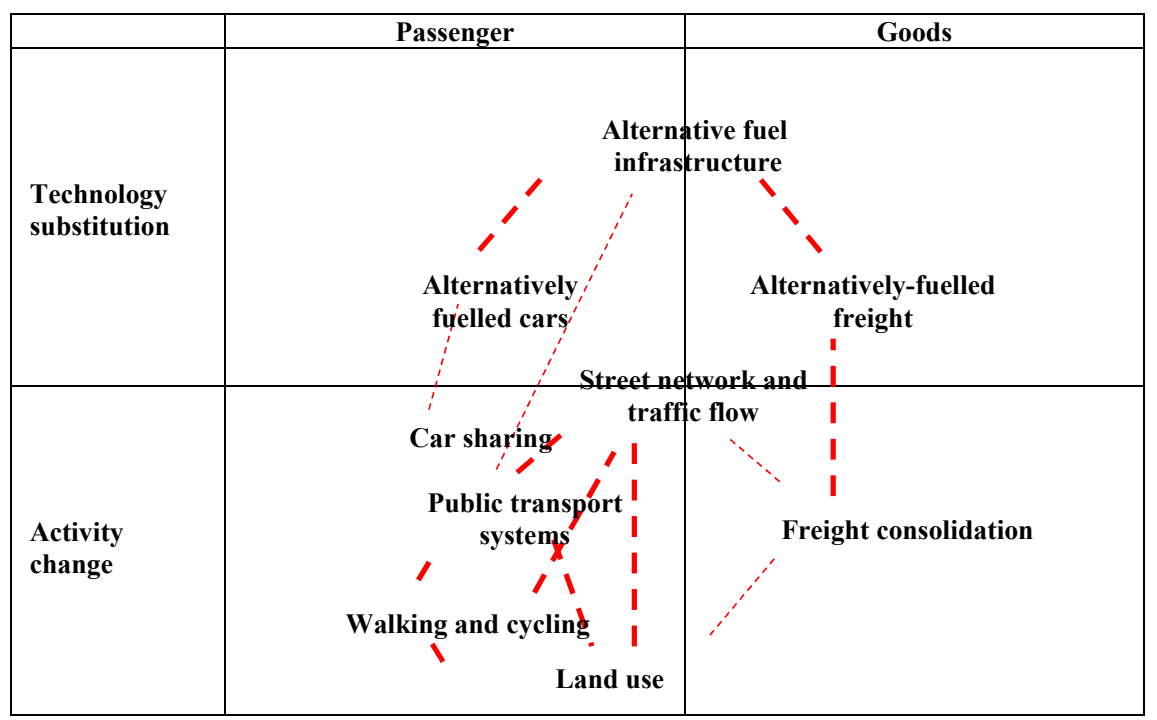

Figure 1: Strategic building blocks for an urban transport strategy. 


\subsubsection{Barriers for change}

Clearly, the building blocks will not implement themselves. For each of the observed areas, different barriers were identified and reviewed.

A key barrier within technological substitution was found to be the risk of new innovative solutions having unexpected effects and losing in competition with other solutions. There is also a conflict between an aim for 'technology neutral' policies, and the need for investments allowing emerging technologies to get a foothold in the first place [12]. Finally, the economic turnover in regard to vehicle fleets and (not least) infrastructure is generally slow. The incremental pace of change in the market is too slow to allow the urban transport goal to be reached in time with technological substitution alone.

Strategies for activity change will face both economic and political barriers. Investment and operation costs for modern public transport systems that can compete with cars are often high, even if significant benefits may be harvested over time. Costs or restrictions on vehicle use that directly target the behaviour for citizens and business often meet resistance [13]. In the case of land-use planning and location decisions, inefficiencies occur when public authorities and private companies do not take the impact of individual decision on the transport system as a whole into sufficient consideration.

In city logistics, a key barrier is that costs and profits of measures such as freight consolidation are unevenly distributed among different interests [14]. It can be difficult to make businesses change their behaviour and operations, even when savings are possible. A serious barrier for strategic action is also the lack of insight among policy makers about how the urban supply chains and the logistics industry works.

These were only a few examples of the potential barriers identified in TRANSFORuM. How did the stakeholders consider the prospects for actually reaching towards the White Paper goal on such a difficult background?

\section{Results}

\subsection{Key messages}

The 'spirit' of the White Paper goal is seen by many as broadly in line with visions and on-going efforts in many cities in Europe already. However, to foster momentum it must be aligned clearly with specific needs and commitments of a broad range of urban transport stakeholders. The goal is one element in a broader vision for attractive, competitive, and resource efficient urban mobility in Europe. Table 1 summarizes the key messages from the stakeholder dialogues. 
Table 1: Key messages from TRANSFORuM on the Urban Transport goal.

\begin{abstract}
Transforming urban mobility requires an open approach
A European roadmap towards the implementation of the White Paper's urban mobility goal needs to adopt a broad and open approach because the required processes of transformation cannot be prescribed from above, given the diversity and specific historical, cultural, economic, environmental and other conditions.
\end{abstract}

\title{
European goals must be aligned with local visions and benefits
}

The overarching concerns for climate change and fuel independence must be aligned with concerns and rationales at the urban level such as improved accessibility, quality of life, safety, health, and prosperity.

\section{Replacing vehicles and fuels is important but not sufficient}

Specific technological solutions such as electromobility still suffer from various limitations. The roadmap for the urban mobility goal must therefore embrace a much wider scope of transport options than simply replacing conventionally-fuelled vehicles with non-conventionally-fuelled ones.

\section{Limiting conventionally-fuelled vehicle use can come at low costs}

The review of possible building blocks for change has emphasised the great potential of many low-cost options for limiting the use of conventionallyfuelled vehicles such as measures to enhance walking, cycling, e-bikes and car-sharing that are not yet widely exploited.

\section{Political momentum must be fostered in many cities}

Although a number of cities stand out as already advancing towards a more sustainable urban transport situation, a majority of cities have not made any significant steps towards the goal or no ambitions to do so are apparent. There is a strong need to identify ways to inspire cities to take action at the political level.

National and state frameworks must support European goals and local actions

Cities need frameworks and active support from national, state and regional governmental levels in areas such as deployment of alternative fuel infrastructure, rules on access restrictions and charging schemes, fiscal incentives, and national frameworks for planning to enhance SUMP.

\section{Communication and knowledge consolidation will advance the learning curve}

A most widely shared observation among stakeholders is the strong need for continued communication, coordination and dialogue. A reinforced dialogue among stakeholders should be prioritised at all levels, and across them, because enhanced dialogue is the best way to move upwards on the learning curve. 


\subsection{Action steps and milestones}

To reach the urban mobility goal of the White Paper it was widely agreed that coordinated actions must be taken by stakeholders at all levels of decision making over an extended period of time, starting now.

The roadmap proposes action at the European, Member State, and urban level. It covers the time from now (2015) to 2030, divided in three main phases when the goal is to be fulfilled. The proposed actions are of two types, called 'processes' and 'measures'. The former include general and enabling frameworks, while the latter are more specific initiatives. It was not considered relevant to prescribe specific measures to be applied in all cities, and member states. The adoption and implementation of detailed instruments and policy packages will have to take the local and national context into account. The roadmap of actions - who has to do what by when - is illustrated by Milestones in the two Tables 2 and 3.

While it is clear the European Union and the local authorities will both be instrumental for the success of a process to realize a European scale goal for cities and urban areas, it is also essential not to overlook the role of the national level. Urban planning frameworks and general transport policies as well as taxation and charging rules remain largely within national jurisdictions and so does the responsibility to ensure roll out of infrastructure for alternative fuels. While European member states have reluctantly agreed to pursue moderately ambitious strategies in the latter field, most of them have yet to fully embrace their important role for transforming the urban mobility culture in Europe.

\section{Conclusions and perspectives}

The TRANSFORuM project was successful in terms of producing the expected output, but even more so in terms of gathering broad support among a very diverse group of stakeholders for a common set of important key messages, and proposals for action. A noteworthy conclusions is, that while a European level urban transport goal focused on cleaner vehicles and logistics can certainly be worthwhile to discuss and explore, it is also clear that a successful strategy towards such a goal needs to be firmly embedded in a wider strategy for sustainable urban development and mobility; where replacing conventional types of vehicles and fuels is an important but not sufficient component. Another strong conclusion is that the diversity of opportunities, resources, experiences, and preferences among European cities is so great that strategies, even for a common goal like the urban transport one will need to be highly diversified as well as closely aligned with the aims and aspirations of local stakeholders and decision makers. It is essential that the TRANSFORuM roadmap is not seen as a terminus, but as rather as a new starting point for a continuously evolving and increasingly well-informed dialogue on how to transform urban mobility and logistics throughout Europe. 
Table 2: Summary of proposed actions at the European and national levels.

\begin{tabular}{|c|c|}
\hline No. & Milestones for actions \\
\hline M1 & $\begin{array}{l}\text { Data, indicators and procedures to measure urban mobility goal performance } \\
\text { resolved }\end{array}$ \\
\hline M2 & $\begin{array}{l}\text { A comprehensive benchmarking system for clean and efficient urban transport } \\
\text { defined }\end{array}$ \\
\hline M3 & $\begin{array}{l}\text { Concept of SUMP recognised by all cities in Europe; 2nd generation SUMP } \\
\text { framework adopted }\end{array}$ \\
\hline M4 & $\begin{array}{l}\text { 3rd generation SUMP integrated as part of wider urban development } \\
\text { frameworks adopted }\end{array}$ \\
\hline M5 & $\begin{array}{l}\text { European platform for cities committing to urban mobility goal formed with } 20 \\
\text { Mayors }\end{array}$ \\
\hline M6 & 100 Mayors have committed their cities to urban mobility goal \\
\hline M7 & A European platform for aspiring cities formed with 50 Mayors \\
\hline M8 & 500 Mayors have joined the aspiring cities platform \\
\hline M9 & $\begin{array}{l}\text { All European cities have committed to urban mobility goal; The platforms are } \\
\text { merged }\end{array}$ \\
\hline M10 & Prestigious award for clean and efficient urban transport launched \\
\hline M11 & $\begin{array}{l}\text { Survey demonstrates high awareness or European urban mobility goal and } \\
\text { strategies }\end{array}$ \\
\hline M12 & $\begin{array}{l}\text { Funding schemes adapted to support aspiring cities investing to reach urban } \\
\text { mobility goal }\end{array}$ \\
\hline M13 & $\begin{array}{l}100 \text { cities have received European support; All funding efficiently spent on } \\
\text { relevant projects }\end{array}$ \\
\hline M14 & $\begin{array}{l}\text { All relevant technical standards to support clean and efficient urban transport } \\
\text { revised/proposed }\end{array}$ \\
\hline M15 & $\begin{array}{l}\text { National programmes for promoting alternative fuels evaluated and new } \\
\text { measures proposed }\end{array}$ \\
\hline M16 & $\begin{array}{l}\text { All Member States have defined how to orchestrate national support for urban } \\
\text { mobility goal }\end{array}$ \\
\hline M17 & $\begin{array}{l}\text { All Member States have reviewed national planning frameworks to support } \\
\text { SUMP }\end{array}$ \\
\hline M18 & $\begin{array}{l}\text { All Central and Eastern European Member States have launched campaigns or } \\
\text { similar }\end{array}$ \\
\hline M19 & $\begin{array}{l}85 \% \text { of citizens in Central and Eastern European Member States express } \\
\text { support to non-conventionally-fuelled vehicles }\end{array}$ \\
\hline M20 & $\begin{array}{l}\text { All Member States have communicated convincing plans for deployment of } \\
\text { alternative fuels }\end{array}$ \\
\hline M21 & $\begin{array}{l}\text { All Member States have implemented effective plans for deployment of } \\
\text { alternative fuels }\end{array}$ \\
\hline M22 & Efficient markets for affordable alternative fuels emerging in all Member States \\
\hline M23 & $\begin{array}{l}\text { All Member States have reviewed legislation to allow cities necessary leverage } \\
\text { over access }\end{array}$ \\
\hline M24 & $\begin{array}{l}\text { All Member States have reviewed legislation to allow cities to restrict non- } \\
\text { zero-emission access }\end{array}$ \\
\hline M25 & All Member States have reviewed taxation schemes \\
\hline M26 & All Member States have national programmes supporting CLSCs \\
\hline
\end{tabular}


Table 3: Summary of proposed actions at the urban level.

\begin{tabular}{|c|c|}
\hline No. & Milestones for actions \\
\hline M27 & $\begin{array}{l}\text { All cities have conducted a stakeholder dialogue on urban mobility goal and } \\
\text { strategies }\end{array}$ \\
\hline M28 & All cities have adopted a certified SUMP by 2020 \\
\hline M29 & $25 \%$ of cities have adopted a second generation certified SUMP by 2025 \\
\hline M30 & $\begin{array}{l}\text { Half of the major cities have established some form of freight transport } \\
\text { partnership }\end{array}$ \\
\hline M31 & $\begin{array}{l}\text { All major cities have established a freight transport partnership following } \\
\text { 'good practice' }\end{array}$ \\
\hline M32 & Most cities have joined city networks for urban mobility goal (=M6 and M8) \\
\hline M33 & $\begin{array}{l}\text { At least } 50 \% \text { of the cities are experimenting with or have implemented } \\
\text { alternatively-fuelled buses }\end{array}$ \\
\hline M34 & $\begin{array}{l}\text { At least } 50 \% \text { of cities committed to only use renewable energy for public } \\
\text { transport }\end{array}$ \\
\hline M35 & $\begin{array}{l}\text { At least } 50 \% \text { of cities have fully switched to renewable energy for public } \\
\text { transport }\end{array}$ \\
\hline M36 & At least $50 \%$ of cities have MIMP system in place \\
\hline M37 & $\begin{array}{l}800 \text { cities have adopted basic pedestrian and cycling networks and strategies, } \\
\text { cycling in European cities increased on average } 100 \% \text { between } 2015 \text { and } 2020 \text {, } \\
\text { with minimal reduction in walking and public transport }\end{array}$ \\
\hline M38 & $\begin{array}{l}400 \text { cities have extensive bike-sharing systems with e-bikes and/or large } \\
\text { secured bicycle parking at public transport nodes; cycling in European cities } \\
\text { has increased on average } 200 \% \text { between } 2015 \text { and } 2025 \text {, with minimal } \\
\text { reduction in walking and public transport }\end{array}$ \\
\hline M39 & $\begin{array}{l}\text { Most cities provide support to car-sharing initiatives, and have adopted } \\
\text { Mobility Management strategies jointly with employers and business parks }\end{array}$ \\
\hline M40 & $\begin{array}{l}\text { At least } 25 \% \text { major cities (that have a legal basis to do so) have introduced } \\
\text { road and/or extensive parking charging favouring non-conventionally-fuelled } \\
\text { vehicles (according to a standard definition) }\end{array}$ \\
\hline M41 & $\begin{array}{l}\text { At least } 25 \% \text { of major cities (that have a legal basis to do so) have introduced } \\
\text { access restrictions favouring non-conventionally-fuelled vehicles (according to } \\
\text { a standard definition) }\end{array}$ \\
\hline M42 & $\begin{array}{l}\text { All major cities have introduced charging or access restrictions favouring non- } \\
\text { conventionally-fuelled vehicles (according to a standard definition) }\end{array}$ \\
\hline M43 & $\begin{array}{l}\text { In } 40 \% \text { of major cities one or more CLSCs have been established, based on a } \\
\text { review of needs and opportunities in the particular context }\end{array}$ \\
\hline M44 & $10 \%$ of urban freight is carried by ZEVs \\
\hline M45 & $25 \%$ of urban freight is carried by ZEVs \\
\hline M46 & $\begin{array}{l}\text { At least } 75 \% \text { of cities have adopted a procurement policy for alternatively- } \\
\text { fuelled mobility }\end{array}$ \\
\hline M47 & $\begin{array}{l}\text { All publicly procured mobility in European cities is zero emissions and based } \\
\text { on renewables }\end{array}$ \\
\hline
\end{tabular}

\section{References}

[1] UN DESA, World Urbanization Prospects. United Nations, New York, 2014. 
[2] EC, Green Paper: Towards a new culture for urban mobility. COM(2007) 551 final. European Commission, Brussels, 25.9.2007.

[3] EC, White Paper. Roadmap to a single European transport area - towards a competitive and resource efficient transport system. COM(2011) 144 final (COM/European Commission). Brussels.

[4] Gudmundsson, H., Schippl, J., Leiren, M., Brand, R., Sørensen, C. H., Anderton, K., Reichenbach, M. TRANSFORuM Roadmap Urban Transport. Cologne: Rupprecht Consult, 2015. Online: http://www.transforum-project.eu/

[5] Austin et al., Moving People: Towards Sustainable Mobility in European Metropolitan Regions. INTERREG IVC Catch-MR project. Joint Spatial Planning Department Berlin-Brandenburg, Berlin. November, 2012

[6] Ahrend R., Gamper, C. \& Schumann, A. The OECD Metropolitan Governance Survey: A Quantitative Description of Governance Structures in Large Urban Areas, OECD Regional Development Working Paper, Paris, 2014.

[7] Rijkee, A.G. \& van Essen, H.P., Review of projections and scenarios for transport in 20 Task 9 Report $\mathrm{V}$ produced as part of contract ENV.C.3/SER/2008/0053 between European Commission DirectorateGeneral Environment and AEA Technology plc, 2012. Online: www.eutransportghg2050.eu

[8] IEA, A Tale of Renewed Cities. A policy guide on how to transform cities by improving energy efficiency in urban transport systems. International Energy Agency, Paris, 2013.

[9] Kuhnimhof, T., Armoogum J., Buehler, R., Dargay, J., Denstadli J.M. \& Yamamoto, T., Men Shape a Downward Trend in Car Use among Young Adults - Evidence from Six Industrialized Countries. Transport Reviews, Vol. 32, Issue 6, pp. 761-779, 2012.

[10] Berger, G., Feindt, P.H., Holden, E. \& Rubik, F., Sustainable Mobility Challenges for Complex Transition. Journal of Environmental Policy \& Planning, 16:3, pp. 303-320, 2014.

[11] Van Dender, K. \& Clever, M., Recent Trends in Car Usage in Advanced Economies - Slower Growth Ahead? Summary and Conclusions. International Transport Forum. Discussion Papers. OECD, Paris, 2013.

[12] Azar, C. \& Sandén, B. A., The elusive quest for technology-neutral policies. Environmental Innovation and Societal Transitions 1, pp. 135139, 2011.

[13] Howarth C. \& Ryley T., Chapter 10: A behavioural perspective on the relationship between transport and climate change. In: Ryley T. \& Chapman L. (Eds.), Transport and Climate Change. Emerald, Bingley, 2010.

[14] Andersen, J. \& Eidhammer, O., New steps in the direction of efficient and environmentally friendly city logistics. Samferdsel 53(8), 2014. 